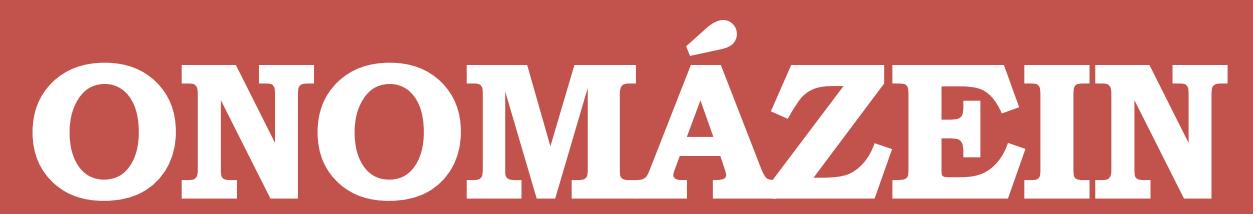

Revista de lingüística, filología y traducción
PONTIFICIA UNIVERSIDAD

\title{
Ad domanda gravia mala multarum gentium: ¿Roma liberadora o Roma represora? En torno a la traducción de De civitate Dei V, 13, 4-5
}

Ad domanda gravia mala multarum gentium: Liberating or Repressing Rome? On Translating De Civitate Dei V, 13, 4-5

\section{José Patricio Domínguez Valdés}

Universidad de los Andes

Chile

\section{(C) $\underset{\mathrm{BY}}{(} \bigodot_{\mathrm{ND}}$}

José Patricio Domínguez Valdés: Instituto de Filosofía, Universidad de los Andes, Chile. | Correo electrónico:jpdominguez@miuandes.cl 


\section{Resumen}

Este breve artículo compara numerosas traducciones modernas de un pasaje clave de De civitate Dei $\vee$ y muestra que la traducción correcta es aquella que enfatiza el concepto negativo de Roma que propone Agustín a lo largo de la obra.

Palabras clave: traducción; De civitate Dei; Agustín; providencia; Roma.

\section{Abstract}

The brief article compares many modern translations of a key passage of De civitate Dei $V$ and shows that the correct translation is the one which emphasizes Augustine's negative concept of Rome, as it is proposed throughout this work.

Keywords: translation; De civitate Dei; Augustine; providence; Rome. 
Ecce quam feliciter Roma vincit tam infeliciter quidquid extra Romam est vincitur. Orosio, Historias $\vee 1$.

\section{Introducción}

Todo traductor se enfrenta, tarde o temprano, a problemas cuya solución escapa al ámbito de lo meramente lingüístico. En estos casos, el conocimiento adecuado de la lengua de origen y de la lengua de destino se muestra insuficiente a la hora de dar cuenta de algún pasaje, pues la clave del sentido del texto se halla más allá del texto, esto es, en su contexto. Por ello resulta obvio que el traductor no sólo ha de ser versado en la lengua desde la cual traduce y hacia donde traduce, sino que debe conocer bien los temas tratados por el autor, su mentalidad, su trasfondo epocal y, si es el caso, su doctrina ${ }^{1}$.

Un breve texto de la monumental obra De civitate Dei contra paganos de Agustín de Hipona pone al lector y traductor en tal situación. Se trata de una frase corta ubicada en De civitate Dei $\mathrm{V}, 13,4-5$ : ad domanda gravia mala multarum gentium². El contexto inmediato de dicha sentencia lo constituye la discusión acerca del papel del imperio romano en el plan de la divina providencia, cuestión importantísima en el plan de la obra³. En efecto, la caída de Roma a manos de los bárbaros el año 410 no sólo sometió a los ciudadanos romanos a una suerte de shock inesperado, sino que la consternación también se apoderó de muchos cristianos que habían asumido la doctrina de la Roma aeterna4 ${ }^{4}$ Para los primeros, la caída de Roma era un motivo para culpar al cristianismo5; para los segundos, la caída de Roma equivalía al fin de los tiempos anunciados en las Sagradas Escrituras ${ }^{6}$. Muchos cristianos no soportaban

1 Este artículo desarrolla una idea presente in nuce en el artículo de mi autoría llamado "El papel providencial del imperio Romano y el katechon de II Tesalonicenses: una lectura desde De civitate Dei”, a publicarse en la revista Pensamiento (España). Agradezco al revisor anónimo de Onomázein por sus correcciones y a Alfonso Herreros por su atenta lectura de la primera versión.

2 Todos los textos citados de De civitate Dei han sido extraídos de la edición crítica de Dombart/Kalb (CCSL, XLVII-XLVIII).

$3 \quad$ civ. I, 36; IV, 2; V, praefatio

4 Cf. Lamotte (1962: 25Ss.). Acerca de los hechos que detonaron la redacción de la obra cf. Bardy (1959: 9-22). Sobre la situación y composición del público cartaginense de los primeros libros de civ. cf. Barnes (1997: 65-75) y McLynn (1999: 345S.).

5 civ. I, 1: sic evaserunt multi, qui nunc Christianis temporibus detrahunt et mala, quae illa civitas pertulit, Christo inputant; civ. I, 3: qui ea mala, quae pro suorum morum perversitate merito patiuntur, blasphemantes Christo inputant.

6 Cf. S. 105, 7, 9 (S. Jerónimo podría contarse entre las autoridades contemporáneas a Agustín que compartían esta idea.), ep. 126, 2; 127, 12; 128, 5. 
la idea de que la ciudad sede de la Iglesia podía ser destruida y caer. Agustín tiene en mente sobre todo al segundo tipo de auditores al intentar formular una respuesta coherente y comprensiva sobre los verdaderos alcances de la caída de Roma en el decurso de la historia de la salvación. Así comienza el capítulo 13 del libro V:

Quam ob rem cum diu fuissent regna Orientis inlustria, voluit Deus et Occidentale fieri, quod tempore esset posterius, sed imperii latitudine et magnitudine inlustrius, idque talibus potissimum concessit hominibus ad domanda gravia mala multarum gentium, qui causa honoris laudis et gloriae consuluerunt patriae, in qua ipsam gloriam requirebant, salutemque eius saluti suae praeponere non dubitaverunt, pro isto uno vitio, id est amore laudis, pecuniae cupiditatem et multa alia vitia comprimentes (civ. V, 13).

\section{Las traducciones}

La más reciente traducción castellana de Marina Sáez reza así: "Por estos motivos, tras haber existido durante largo tiempo los florecientes reinos de Oriente, Dios quiso que surgiera también uno en Occidente que fuese posterior en el tiempo, pero más floreciente en la extensión y la grandeza de su hegemonía, y a fin de poner frenos a los graves males que sufrían muchos pueblos, se lo cedió especialmente a personajes tales, que aspirando al honor, la alabanza y la gloria, velaron por la patria, en la cual buscaban esa misma gloria, y no dudaron en anteponer la salvación de ésta a la suya propia, reprimiendo el ansia de dinero y muchos otros vicios por este único vicio, esto es, el amor a la alabanza” (Marina Sáez, 2007).

La traducción sortea bien la estructura sintáctica del latín y entrega una versión casteIlana inteligible y pulcra. Sin embrago, la claridad de la traducción nos podría engañar y hacernos pensar que se trata de un texto simple y claro. Pero lo cierto es que, como notó Gerosa hace ya muchas décadas, se trata de un texto que deja muchas cuestiones abiertas (Gerosa, 1931: 1009). Agustín sitúa a Roma como el último de los cuatro regna que dominan el mundo después del imperio asirio, el imperio persa y el imperio macedonio (cf. civ. IV, 7.) Roma, el último y más poderoso de estos cuatro imperios, sería una comunidad formada por individuos patriotas movidos por el amor a la alabanza y su finalidad providencial sería el poner freno a los graves males que sufrían muchos pueblos (ad domanda gravia mala multarum gentium). Como se echa de ver, la traductora opta por traducir gravia mala en un sentido pasivo: son los males sufridos por muchos pueblos los que terminan con el imperio romano. Desde esta perspectiva, Roma es bienhechora de los pueblos conquistados. Galos, dacios, celtas, sirios, egipcios y judíos, entre otros, serían presentados como pueblos aquejados por desgracias que menguan gracias a la conquista romana. La misma línea sigue la traducción de Santamarta del Río y Fuertes Lanero (1977). Allí leemos que Dios puso a Roma como imperio con el fin de "atajar los graves males que padecían muchas naciones". Este camino lo secunda también R. 
W. Dyson en su elogiada traducción: "In order that it might overcome the great evils which had afflicted many other nations" (Dyson, 1998).

A la opción de estos tres traductores no puede achacársele error alguno en el plano lingüístico. El sustantivo malum en latín, al igual que el sustantivo castellano mal, es lo bastante amplio para significar algo malo que se padece o algo malo que se hace (es decir, una acción mala, y por ende culpable). Desde el punto de vista de la traducción, enfatizar el aspecto pasivo de malum en desmedro de otro es una elección legítima. En efecto, dicho sustantivo aparece numerosas veces y en pasajes claves de la Ciudad de Dios usado en el sentido de mal padecido, desgracia, calamidad. El libro primero de De civitate Dei, que intenta consolar a las víctimas del desastre de 410 respondiendo a la pregunta de por qué Dios permite que ocurran las calamidades que ocurren (como los saqueos, los pillajes, las violaciones), ofrece numerosos ejemplos de este uso.

Limitémonos a cuatro: (1) civ. I, 1: sic evaserunt multi, qui nunc Christianis temporibus detrahunt et mala, quae illa civitas pertulit, Christo imputant; (2) civ. I, 3: qui ea mala, quae pro suorum morum perversitate merito patiuntur; (3) civ. I, 8: Nam bonus temporalibus nec bonis extollitur nec malis frangitur; (4) civ. I, 9: Non mihi itaque videtur haec parva esse causa, quare cum malis flagellentur et boni. Los verbos de padecimiento que acompañan al sustantivo malum (perfero, patior, frangor, flagellor) hacen necesaria la comprensión o traducción de malum por "desgracia".

Algo similar podría decirse de la traducción de malum con verbos de acción o acompañadas de algún indicio que indique su carácter activo. Así, las frases Cur autem homo, qui mali nihil fecit (civ. I, 17), malo consentire (civ. I, 18) o mala oriantur in moribus (civ. I, 30, 12) apuntan al sentido de mal activo, ya como acción mala o como disposición mala, i. e. vicio. Quizá la frase más ilustrativa de ambos sentidos del sustantivo malum sea la que se encuentra en civ. I, 33. Allí Agustín les reprocha a los romanos el no querer imputarse a sí mismos los males que cometen, pero sí culpar a los "tiempos cristianos" de los males que sufren: Hinc est quod mala, quae facitis, vobis imputari non vultis, mala vero, quae patimini, Christianis temporibus imputatis (civ. I, 33).

Sin embargo, en nuestro pasaje en cuestión el sustantivo malum no aparece acompañado de ningún verbo u otro indicio que nos permita a primera vista comprenderlo y traducirlo

7 Cf. también civ. I, 24: Nolunt autem isti, contra quos agimus, ut sanctum virum lob, qui tam horrenda mala in sua carne perpeti; civ. I, 29: malis autem aut probatur aut emendatur; civ. I, 29: pro toleratis pie malis temporalibus servat.

8 Cf. también civ. I, 30: tanta de rebus prosperis orta mala continuo subsecuta sunt; deinde mox malarum conexione causarum bellis etiam civilibus tantae strages ederentur. 
en sentido pasivo (“desgracia”) o activo (“vicio”). Quizá por esta ambigüedad ha habido también un número considerable de traductores que han optado por traducir mala por "males" simpliciter, sin añadidos que apunten en uno u otro sentido. Tal es el caso de Bettenson: "to suppress the grievous evils of many nations" (Bettenson, 2003); de Jerphagnon y otros: "pour réduir le mal accablant de nombreux peuples" (2000); de la traducción decimonónica de Ottavio Gigli: "domari li grandi mali di molte genti” (Gigli, 1842) y de J. Morán: "para amansar los graves males de muchas naciones" (Morán, 1958). Podríamos añadir en este grupo la reciente traducción de Babcock (que sigue casi sin modificación la traducción decimonónica de M. Dods): "in order to counteract the terrible evils of many other peoples" 9 . En estas traducciones se conserva la ambigüedad del latín, de suerte que no sabemos si Agustín se refiere a los males que sufrían dichos pueblos, y que el imperio romano vino a remediar, o si más bien se trata de males que dichos pueblos cometían, y que Roma vino a reprimir.

Por último, existe un grupo de traductores que entienden gravia mala como los vicios o inmoralidades de dichos pueblos, no como males sufridos por ellos. Este tercer tipo de traducción apoya su fuerza en la traducción de malum como "vicio" o y en la traducción del verbo domo en el sentido de "reprimir", "castigar". Así, Combès traduce: "et pour réprimer les graves vices de maintes nations"(Combès, 1980). La traducción alemana de Thimme parece tomar este camino: "um in vielen Völkern schwere Übelstände zu unterdrücken"10. Forma también parte de este grupo la elección de Green y de Walsh: "To overcome the grievous vices of many nations" (Green, 1963) y "to ensure the suppression of grievous abuses in many nations" (Walsh, 2009) respectivamente. Lo mismo la traducción castellana de Riber y Bastardas: "con el fin de domar las graves culpas" (Riber y Bastardas, 1992). La traducción italiana de Gentili y la francesa de Moureau son aún más explícitas: "per punire la grave immoralità di molti popoli”11 y “pour châtier le crime de tant de peuples" (Moreau, 1994), respectivamente.

Con seguridad, la razón de más peso para interpretar así la frase viene dada por el verbo domo. El verbo domo proviene del ámbito agrario y significa en primer lugar (1a) domar, amansar un animal12. Los diccionarios más completos catalogan una serie de usos más o menos traslaticios que se derivan de este uso primario: (1b) En el plano de los entes inertes, se

9 W. Babcock (2012). La traducción de M. Dodds reza así: "And, in order that it might overcome the grievous evils which existed among other nations".

10 W. Thimme (1997). Sin embargo, se podría decir que al traducir mala por Übelstände Thimme deja abierta la cuestión de si se trata de desgracias o vicios.

11 Gentili (1997). La misma elección tomó la traducción decimonónica francesa a cargo de Poujoulat y de M. Raulx (1864) omitiendo incluso gravia mala: "pour châtier un grand nombre de nations".

12 Cf. Thesaurus linguae Latinae vol. V 1, p. 1943, lín. 41 - p. 1948, lín. 52; Der neue Georges ad loc.; Glare Oxford Latin Dictionary ad loc. 
puede domar también a un río (i. e., contenerlo), a un campo (i. e., cultivarlo) o un terreno (hacerlo habitable). (2a) En el plano humano, domar a una persona significa reducirla, corregirla o vencerla; domar una ciudad o un pueblo significa subyugarlo o conquistarlo. (2b) En el plano psicológico o ético, domare se aplica a otras relaciones entre "poderes" concebidos políticamente, como el cuerpo y el alma, las diferentes facultades del alma misma o el yo y sus impulsos o vicios. Es en este ámbito (llamémoslo 2c para separarlo de los anteriores, aunque también podríamos subsumirlo bajo 2a) donde se encuentra atestiguado uso de domare, menos frecuente, como castigar (cuyo objeto no es una persona, como en el uso 2a, sino un aspecto o acto de esta). Claudiano (370-405), un autor contemporáneo a Agustín, por ejemplo, elogia al cónsul y hombre de letras Manlio Toedoro por su moderación y serenidad a la hora de "corregir (corrigere) a los criminales" y "domar (= castigar) sus delitos"13.

Todos estos usos de domare se encuentran también en Agustín. En la misma obra De civitate Dei encontramos el uso de domare en el sentido 1a-b (civ. XXII, 24: in capiendis occidendis domandis irrationabilibus animantibus quae et quanta reppererit) ${ }^{14}$; y en sentido 2a (civ. XXII, 22: Quid paedagogi, quid magistri, quid ferulae, quid lora, quid virgae, quid disciplina illa, qua Scriptura sancta dicit dilecti filii latera esse tundenda, ne crescat indomitus domarique iam durus aut vix possit aut fortasse nec possit?; civ. III, 26: Romanum maxime praepollebat imperium, tamquam saeva barbaries domarentur). El sentido 2b (ético-ascético) se encuentra en otras obras, por ejemplo, en ep. 177, 1: domare et exstinguere omnes cupiditates; y en c. Iul. II, 8, 24: Ergo princeps et domina carnis naturaliter anima est, quae domare carnem debet et regere. El uso 2c aparece explícitamente Agustín en S. 13. Allí el Hiponense, comentando el Salmo 2, 10 "educaos, todos los que gobernáis la tierra" (erudimini omnes qui iudicatis terram), señala que "juzgar la tierra" significa corpus domare, explicando esto último en referencia a las palabras de san Pablo en I Cor 6, 26: "escuchemos al apóstol juzgar la tierra: no lucho, dice, como quien azota el aire, sino que castigo mi cuerpo [castigo corpus meum] y lo esclavizo, no sea que predicando a otros resulte yo descalificado". Los cristianos, dice el Hiponense, deben "juzgar la tierra” en el sentido de castigar sus cuerpos y refrenar los deseos ${ }^{15}$.

En suma: el giro domare gravia mala en Agustín es coherente con este uso translaticio del verbo domare como "castigar". Desde un punto de vista meramente lingüístico, esta tercera

13 Cf. Claudiano, Cons. Mall. Et Theod. 222; cf. también Silio Itálico, Punica XIII, 845.

14 Cf. también I0. ev. tr. I, 15: populum Pharaonis superbum potuit Deus domare de ursis, de leonibus, de serpentibus; muscas et ranas illis immisit.

15 s. 13: si autem terram non iudicaueris, terraeris. si autem terra fueris, ad eum pertinebis cui dictum est: terram manducabis. audiant ergo iudices terrae. Corpus castigent, libidines frenent, ament sapientiam, uincant concupiscentiam. et ut hoc faciant, erudiantur. 
alternativa de traducción es perfectamente legítima. ¿Cómo decidir entre las tres alternativas de traducción? El modo de resolver esta cuestión, como enunciamos al principio del artículo, supera la esfera meramente semántica y exige afinar la mirada sobre el contexto de la obra De civitate Dei. En concreto, se trata aquí de determinar qué idea precisa de Roma tiene Agustín para saber si la frase en cuestión describe a Roma como una liberadora de pueblos que padecen muchas desgracias o más bien como una castigadora de pueblos viciosos, o si la cuestión queda abierta por falta información relevante en uno u otro sentido.

\section{Solet corruptos hominum mores bellis emendare}

Esta discusión, que podría parecerle a alguien quizá demasiado rebuscada, se entronca sin embargo con una discusión de larga data en la literatura especializada sobre la visión agustiniana del imperio romano. Y se podría decir aún más: este problema erudito sobrepasa el campo de los estudios agustinianos; dado que Agustín es una de las fuentes principales en la construcción de la cosmovisión de la cristiandad medieval y moderna temprana, se comprenderá que su valoración del imperio romano en particular, y del poder político en general, ha incidido significativamente en las querellas entre el poder terrenal y el poder espiritual o en la cuestión de la justificación teológica del poder imperial ${ }^{16}$. En pleno siglo XVI, por ejemplo, el texto fue usado como una auctoritas por Ginés de Sepúlveda para defender el papel providencial que le tocaba a los españoles en la conquista de los indios, a saber, el ser instrumentos de la providencia en la represión del vicio de los pueblos aborígenes americanos (Lupher, 2003: 115-116). Obviando la discusión de si a algún imperio posterior le pertenecen las facultades concedidas a Roma, cabe preguntarse dos cosas: (1) si Ginés de Sepúlveda acertaba interpretando gravia mala como "vicios" (y, por consiguiente, domare como castigar) y (2) si estaba en lo cierto al extraer de este texto una imagen positiva de Roma (o del poder imperial, en su caso), que pudiese servir para legitimar teológica y jurídicamente su expansión y sus conquistas.

Creo que a partir de la caracterización de Roma en De civitate Dei tendremos que responder positivamente a la primera pregunta y negativamente a la segunda. Dicho de otro modo, para Agustín Roma sí tuvo un papel providencial en la "historia universal”, a saber, el de castigar y refrenar los vicios de los pueblos vecinos, pero, al mismo tiempo, este poder es concebido como una virtud ambigua o relativa ${ }^{17}$, no como una virtus en el sentido pleno, de suerte que no cabe establecer una legitimación ética del papel providencial de Roma.

16 Cf. el clásico estudio de Arquillière (1955). Para un balance cf. Beyer de Ryke (1999).

17 Sobre el concepto de virtus pagana en Agustín cf. Harding (2011: 71-102). 
Como señalé anteriormente, sobre el concepto agustiniano de Roma se ha debatido bastante. Sin embargo, muchas veces se echa de menos distinciones que podrían ser de gran ayuda para distinguir planos de análisis, pues Agustín usa el término de modo bastante plástico y en acepciones diferentes. A partir del juicio negativo de Agustín sobre Roma y su imperialismo, algunos estudiosos han arriesgado la tesis de que la actitud de Agustín con respecto al poder político en cuanto tal es negativa, como si para Agustín estado e imperium romanum fuesen sinónimos ${ }^{18}$. Por otro lado, hay quienes concluyen una visión "positiva” de Roma a partir de sus sinceros lamentos sobre la caída de Roma y su exhortación por una regeneración del imperio (Arbesmann, 1954: 193, 195) o a partir de la utilización del poder coactivo estatal en el caso del donatismo. Para dilucidar estas ambigüedades, es necesario distinguir al menos tres significados de Roma: a) Roma como imperio romano pagano, b) Roma como prototipo de poder político y c) Roma como imperio oficialmente cristianizado.

Si el cometido de nuestro artículo, i. e., cuál es el concepto de Roma que nos permite comprender bien la frase ad domanda gravia mala multarum gentium, dependiese de la elucidación de (b) y (c), tendríamos dificultades que escaparían al alcance de lo aquí propuesto. Pero no es el caso. El libro V de De civitate Dei es la coronación de una pregunta planteada a finales del primero: por qué costumbres suyas y por qué causa Dios ayudó a los romanos a

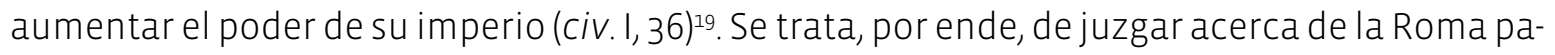
gana, aquella que nace míticamente con Eneas, que le rinde culto a una infinidad de deidades y que piensa que su misión divina es, como dice Virgilio, "perdonar a los vencidos y aplastar a los soberbios" (civ. l, praef.).

Establecido esto, la respuesta a nuestra pesquisa se torna más expedita. Los textos de los primeros cinco libros de De civitate Dei narran la historia romana como un decurso marcado por los excesos y vicios. En particular, el desarrollo de Roma a partir de la victoria en las Guerras Púnicas es explicado como un despliegue del "deseo de dominio" (Iibido dominandi)20: la libido dominandi es el motor de la historia política romana. Ella es la fuerza que carcome a la república romana por dentro mediante sediciones y guerras civiles, y luego explota hacia afuera, afectando a los demás pueblos:

esta misma ansia de poder que, entre otros vicios del género humano, era inherente en su forma más pura al conjunto del pueblo romano, después que venció sobre unos pocos pueblos podero-

18 Cf. Goar (1988: 15-16). Una revisión de estas posturas se halla en Burnell (1992).

19 Deinde mostrandum est, quos eorum mores et quam ob causam Deus verus ad augendum adiuvare dignatus est. Cf. también IV, 2; V, praef.

20 Para el uso del término libido cf. las referencias en Cipriani (2004-2010). 
sos, también oprimió bajo el yugo de la esclavitud a los restantes, pisoteados y fatigados (civ. l, 30, trad. Marina Sáez con modificaciones)21.

Este texto nos entrega la clave para discernir si Roma actúa como liberadora o como represora. A la luz de este texto no queda duda de que se trata de lo segundo. Los pueblos conquistados por Roma aparecen en este pasaje no como salvados, sino como oprimidos y castigados. Agustín sostiene ahí que Roma rara vez respetó el ideal virgiliano de parcere subiectis y que lo usual que ha ocurrido es que Roma devasta al pueblo vencido. El imperio romano es, desde este punto de vista, un agente castigador o probador de la providencia divina. En efecto, las desgracias que sufre un pueblo o una persona, según dice Agustín repetidas veces en el primer libro de De civitate Dei, son permitidas por Dios o bien para castigar los vicios o para probar la virtud (civ. I, 1; I, 8, I, 29)22. En el caso de los pueblos conquistados, se trata más bien de vicios: Ia iniquidad (iniquitas) de estos pueblos los hizo merecedores, por así decirlo, de la reprimenda romana (civ. IV, 15) ${ }^{23}$. Roma no actúa providencialmente como benefactora de pueblos que sufren, sino que les inflige males y desgracias, de suerte que de allí la providencia inescrutable extraiga efectos buenos, como el castigo del vicio y (eventualmente) acrisolamiento de la virtud (cf. civ. I, 8).

Para Agustín, Roma pacifica el orbe a punta de violencia, y su constitución se parece a la de un cuerpo hipertrofiado que sufre en sus miembros desproporcionados por su afán desmedido de crecer (civ. III, 10). A partir de una lectura no forzada de estos textos es imposible no afirmar con Pöschl que Agustín es "el gran cancelador de la misión romana y el gran negador del sentido de la historia romana” (Pöschl, 1955: 957). Desde el punto de vista político, un mundo pacífico optaría por la existencia de pequeños reinos que conviven unos con otros y no por un imperium gigantesco: "así, para mayor felicidad de los asuntos humanos, todos los reinos serían pequeños, gozando de una armoniosa vecindad, y, de ese modo, habría en el mundo muchos reinos, como hay en las ciudades muchas familias de ciudadanos" (civ. IV, 15, trad. Marina Sáez con modificaciones). Más adelante en la obra, por su parecido político con la grande megalópolis oriental y usando una imagen bíblica tremenda, Roma es Ilamada por Agustín “la Babilonia occidental” (civ. XVI, 17) o "segunda Babilonia” (civ. XVIII, 2). El hecho de que Roma haya sido fundada míticamente por un fratricida, Rómulo, le sirve de indicio a Agustín para afirmar que Roma es el arquetipo de la civitas humana (civ. XV, 5). Como señaló

21 civ. I, 30: Ut Romani illi, qui vita integriore mala metuebant ab hostibus, perdita integritate vitae crudeliora paterentur a civibus; eaque ipsa libido dominandi, quae inter alia vitia generis humani meracior inerat universo populo Romano, postea quam in paucis potentioribus vicit, obtritos fatigatosque ceteros etiam iugo servitutis oppressit.

Cf. también Gen. Litt. 3, 15, 24. 
Kamlah, la Roma pagana es para Agustín la encarnación de la civitas diaboli (Kamlah, 1951: 176). A partir de estos textos se hace imposible afirmar que Roma es un agente providencial positivo en la historia universal, en el sentido de ser un poder que con su virtud y bondad contagie a los pueblos circundantes. Su papel es otro: ser un instrumento de justicia vindicativa por parte de la providencia mediante el castigo a los pueblos vecinos viciosos. Difícilmente, por lo tanto, Roma puede ser considerada una liberadora de pueblos oprimidos, como las logradas traducciones de Marina Sáez y Dyson sugieren.

\section{A modo de conclusión}

A partir de lo dicho, resulta razonable pensar que la comprensión y traducción de la frase ad domanda gravia mala multarum gentium necesita de una reflexión ulterior acerca del contexto filosófico agustiniano de la obra De civitate Dei, en particular de la crítica de Agustín al imperio romano como entidad pagana. Desde la comprensión de Roma como un poder político determinado por la libido dominandi y no por la mitigación o remedio de las desgracias que sufren los pueblos vecinos se echa de ver que una traducción fiel al texto tiene que optar por traducir malum por "vicio" y domare por "castigar". En efecto, Roma se expande injustamente (en la medida en que la motivación final de su acción es un deseo desordenado) pero a su vez castiga justamente las iniquitates de los puebles vecinos. El imperium Romanum es, en definitiva, un mal que pone freno a otros males. Creo que esta comprensión pesimista —si se quiere usar este adjetivo - del imperio romano es el mejor argumento para ver en Agustín a un escéptico de la visión providencialista de Roma, ya en su variante pagana, ya su variante cristiana.

La grandeza del imperio romano es para Agustín algo providencial, no en el sentido de que Dios lo haya ungido para una misión divina (por ejemplo, la expansión de la humanitas en un mundo bárbaro o la expansión del Evangelio gracias a su pax romana), sino en el sentido de que Dios le concedió el papel de castigador y dominador del orbe, y estos papeles los recibió merecidamente (civ. V, 14), pues su vicio de libido dominandi, paradójicamente, contiene algo de virtud, a saber, el ser capaz de refrenar otros vicios más viles mediante su afán de gloria y su sentido de bien común (pro re communi24), el ser un agente disciplinador, ascético y moderador del orbe (Bonner, 1990). Más allá del reconocimiento de esta grandeza romana, Agustín no muestra ninguna simpatía patriótica por el imperio del cual formaba parte y se muestra totalmente apático con respecto a los logros bélicos de Roma (Oroz, 1976). Bien podríamos decir que Agustín contempla el imperio romano no como romano, sino como aspi- 
rante a miembro de otra ciudad, la civitas Dei. Desde esa perspectiva podemos entender que Agustín exclame: “¿Qué importa bajo qué imperio vive el hombre destinado a morir, mientras sus gobernantes no le obliguen a realizar acciones impías e inicuas?” (civ. V, 17)25. Que el poder político no obligue al hombre a la impiedad o a la inmoralidad: mientras esas condiciones se cumplan, Agustín se muestra distante con el grandioso imperio que lo vio nacer, cuya limitada virtus no le daría más derecho que el de castigar a pueblos más viciosos que él.

\section{Bibliografía citada}

Agustín de Hipona, De Civitate Dei Contra Paganos (civ). 1955. Ed. Dombart/Kalb, CChr.SL 47-48. Brepols: Turnhout

Agustín de Hipona, De Genesi ad litteram (Gen. litt.). 1984. CSEL 28.1. Viena: De Gruyter.

Agustín de Hipona, Epistulae (ep.). 1994 SS. CSEL 34/2, 539-744; CSEL 44, 1-736; CSEL 57, 1-656. Viena: De Gruyter.

Agustín de Hipona, In Ioannis Evangelium tractatus (Io. ev. tr.). 1954. CChr.SL 36. Brepols: Turnhout. Agustín de Hipona, Sermones (s.). 1862. París: Patrologia Latina (PL) 38.

Arbesmann, Rudolph, 1954: "The Idea of Rome in the Sermons of St Augustine", Augustiniana IV, 305-24.

Arquillière, Henri-Xavier, 1955: L'augustinisme politique. Essai sur la formation des théories

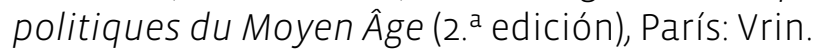

BABcock, William (trad.), 2012: Augustine. The city of God, Translation for the XXIst Century, Nueva York: New City Press.

Baier, Thomas, y Tobias Dänzer (eds.), 2002: Der neue Georges: Ausführliches Handwörterbuch Lateinisch-Deutsch, Darmstadt: WBG.

Bardy, Gustave, 1959: La Cité de Dieu. Introduction génerale et notes, París: Institut d’Études Augustiniennes.

Barnes, Timothy, 1997: "Aspects of the Background of the City of God" en Augustine (ed. by J Dunn / I. Harris), Cheltenham, 2, 138-154.

25 Quantum enim pertinet ad hanc vitam mortalium, quae paucis diebus ducitur et finitur, quid interest sub cuius imperio vivat homo moriturus, si illi qui imperant ad impia et iniqua non cogant? 
Bettenson, Henry (trad.), 2003: Augustine. The City of God, Londres: Penguin.

BEyER DE RYKe, Benoit, 1999: “L'apport augustinien : Augustin et l'augustinisme politique” en A. Renaut (ed.) : Histoire de la philosophie politique, tomo II, Naissance de la Modernité, París: Calmann-Lévy, 43-86.

BonneR, Gerald, 1990: "Perceperunt mercedem suam: The Background and Theological Implications of 'De civitate' V.15”, Studia patristica 18/4, 3-7.

Burnell, Peter, 1992: "The Status of Politics in St. Augustine's City of God", History of Political Thought 13, 132-149.

Ciprianı, Nello, 2004-2010: Voz “libido” en Augustinus-Lexikon 3, Basilea: Schwabe, 981-985.

Claudiano. Panegyricus de Consulatu Flavii Manlii Theodori. 1922. Ed. Platnauer, Cambridge: Loeb.

Combes, Gustave (trad.), 1981: Augustin. La cité de Dieu, París: Bibliothèque Augustinienne.

Dyson, Robert (trad.), 1998: Augustine. The City of God against the Pagans, Cambridge: Cambridge University Press.

GentILI, Domenico (trad.), 1997: Agostino. La città di Dio, Roma: Città Nouva.

Gerosa, Pietro, 1931: "S. Agostino e l'imperialismo romano", Miscellanea Agostiniana 2, 977-1040.

GıGl, Ottavio (trad.), 1842: Della Cittá di Dio (De civitate Dei) di Santo Aurelio Agostino, Roma: Tipografía Salviucci.

GlaRe, Peter (ed.), 1996: Oxford Latin Dictionary, Oxford: Oxford University Press.

Goar, Robert, 1988: "Reflections on Some Anti-Roman Elements in De Civitate Dei, Books I-V", Augustinian Studies 19, 71-84.

Green, William (trad.), 1963: Augustine. City of God, vol II, Cambridge: Loeb Classical Library.

HaRdIng, Brian, 2011: Augustine on Roman Virtue, Londres: Bloomsbury.

Jerónimo, Epistulae. 1918. CSEL 56, 144, 154, 161. Viena: De Gruyter.

Jerphagnon y otros (trads.), 2000: Saint Augustin. La Cité de Dieu, París: Gallimard.

KamLaH, Wilhelm, 1951: Christentum und Geschichtlichkeit, Stuttgart: Kohlhammer.

LAMOTTE, Jean, 1962 : Le mythe de Rome "Ville éternelle" et saint Augustin, Lovaina: Institut Historique Augustinien, 
LuPHeR, David, 2003: Romans in the New World. Classical Models in sixteenth-century Spanish America, Michigan: University of Michigan Press.

Marina Sáez, Rosa (trad.), 2007: San Agustín. La Ciudad de Dios. Libros I-VII. Madrid: Gredos.

McLynn, Neil, 1999: "Augustine’s Roman Empire" en Mark Vessey y otros (eds.): History, Apocalypse, and the Secular Imagination, Ohio: Philosophy Documentation Center, Bowling Green State University.

Morán, José (trad.), 1958: La Ciudad de Dios, Madrid: B. A. C.

Moreau, Louis (trad.), 1994: La cité de Dieu Saint Augustin, traduction du latin de Louis Moreau revue par Jean-Claude Eslin, introduction, présentation et notes par Jean-Claude Eslin, París: Éditions du Seuil.

Oroz Reta, José, 1976: “La romanidad de San Agustín”, Estudios Clásicos, tomo 20, n. 7 3, 353-369.

Pöschl, Viktor 1955: "Augustinus und die römische Geschichtsauffassung" en Augustinus Magister. Congrès International Augustinien, Paris, 21-24 septembre 1954, tomo 2.

Poujoulat y Raulx (trads.), 1864: La cité de Dieu, L. Guérin \& Cie. Bar-le-Duc.

Riber, L. y J. BAStARDAS (trads.), 1992: La Ciudad de Dios, tomo II, Madrid: CSIC.

Santamarta del Rio y Fuentes Lanero (trads.), 1977: San Agustín. La Ciudad de Dios, Madrid: Biblioteca Autores Cristianos.

Silıo Itálıco, Punica. 1932. Ed. Duff. Cambridge: Loeb Classical Library.

Thesaurus linguae Latinae, 18945s. Berlín: Walter De Gruyter.

Thimme, Wilhelm (trad.), 1977: Augustinus. Vom Gottesstaat, Munich: Deutscher Taschenbuch Verlag.

Walsh, Peter, 2009: Augustine: De Civitate Dei: Bks. I \& 2: City of God, Liverpool: Aris \& Phillips Classical Texts. 